\title{
A Resistência Olha a Resistência ${ }^{1}$
}

\author{
Jorge Ponciano Ribeiro \\ Universidade de Brasília
}

\begin{abstract}
RESUMO - Resistência é um processo humano que acontece quando a pessoa se encontra sob algum tipo de ameaça. Não é essencialmente um acontecimento psicoterapêutico. Ocorre na terapia não como uma oposição a si mesmo ou ao terapeuta, mas como uma forma de se ajustar a uma nova situação. A resistência, é por natureza, a atualização do instinto de auto-preservação. E o organismo inteligentemente segue a lei da preferência. Resistência é uma forma de contato que não pode ser destruída, mas administrada, porque ela surge como uma defesa da totalidade vivenciada pela pessoa. A Resistência é, às vezes, resistência e awareness mais que ao contato. Ela revela mais o caminho seguido do que oculta a caminhada feita. A resistência é um processo natural, porque o corpo que não resiste, morre, mas falamos em processos de auto-regulação organísmica. Valorizamos mais o que mantêm a resistência funcionando do que à própria resistência. O terapeuta também resiste, ou seja, ele se auto-regula na sua relação com o cliente. Não questionamos a resistência, mas o processo que a mantêm. Trabalhamos com nove mecanismos de defesa, também tradicionalmente, chamados de resistência.
\end{abstract}

Palavras-chave: resistência; fenomenologia existencial; gestalt terapia; processo grupal.

\section{The Resistance Facing the Resistance}

\begin{abstract}
Resistance is a human process that happens always that the person is under menace or is in position of defending his right to be self-regulated. Resistance is not, by nature, a given psychotherapeutic process. It occurs in psychotherapy, not as an opposition process against himself or to the therapist, but as a function of helping a new situation inside the person. Resistance is, by nature, the actualization of the instinct of self-preservation. That is, everything that is born deserves to live, everything that emerges from the organism emerges as a necessity of the organism, that always follows of the preference law, no matter the nature of the object under observation. Resistance is a contact form that cannot be destroyed, but managed, controlled, because it emerges as a defense of the totality in action. Resistance is, sometime, resistance to awareness, not to contact, even if resistance is a contact form. We don't use to work with the resistance, as resistance, indeed, because if the body does not resist, it dies. We work rather the process than with the resistance in itself. The therapist also resists, it is, and even he also experiences his own self-regulation. What is generally called resistance, we call organic self-regulation process, and we work with mine of these mechanisms.
\end{abstract}

Key words: resistance; existential phenomenology; gestalt therapy; group process.

A proposta deste trabalho é: re-olhar " $O$ Conceito de Resistência na Psicoterapia Grupo Analítica: Repensando um Caminho" (Ribeiro, 1989), e dizer como eu vejo hoje o que escrevi, há quase 20 anos. Pois bem, re-olhando este artigo, vejo hoje, com mais clareza do que vi no passado, o lado fenomenológico da obra de Siegmund Heinrich Foulkes. Como psicanalista e terapeuta de grupo, Foulkes foi absolutamente original, corajoso e atual ao introduzir uma postura fenomenológica na condução de seus grupos.

Como psicanalista e terapeuta de grupo, Foulkes foi absolutamente original, corajoso e atual ao introduzir uma postura fenomenológica na condução de seus grupos. Não é de admirar que, tendo sofrido a influência direta de Kurt Lewin e de Kurt Goldstein, concebia o grupo como um campo

1 Este trabalho foi executado a partir do Capítulo VII "Resistência Grupal" do meu livro "Gestalt Terapia: O processo Grupal. Uma visão fenomenológica, da Teoria do Campo e Holística" da Summus Editorial - São Paulo (1994).

2 Endereço: Departamento de Psicologia Clínica, Instituto de Psicologia, Universidade de Brasília, Campus Universitário Darcy Ribeiro, Asa Norte, ICC sul, Brasília, DF, Brasil 70910-900. E-mail: jorgeponcianoribeiro@yahoo.com.br de forças e fez da noção de campo um dos elementos mais pedagógicos de sua obra. Experenciando o grupo como um campo, como uma miniatura da vida, desenvolveu e introduziu na sua obra uma profunda compreensão do social, vendo o grupo como algo que devia dar respostas precisas às necessidades que afligiam seu tempo, nas circunstâncias de uma guerra, em pelo conflito.

“(...) em espírito, todo grupo deve ser 'aberto'. Aberto, isso é,
orientado para a comunidade e realidade das coisas existentes.
O mundo da realidade, o Corpo e a Comunidade são os coor-
denadores de todas as terapias (Foulkes, 1948, p. 157).
"A vida exterior não é tão diferente da sociedade em miniatura
da análise de grupo e, ao menos em espírito, todo grupo é um
grupo aberto ao livre oceano da vida exterior” (Foulkes \&
Anthony, 1957, p. 133).

A Inglaterra se encontrava em guerra com a Alemanha. Os soldados voltaram do front totalmente perturbados. Precisavam se recompor, se rever. O método clássico da psicanálise não respondia a demanda de tantos soldados, completamente destroçados psicologicamente, e foi nesse 
contexto, na década de 1940, que Foulkes viu no grupo uma possível saída para responder, adequadamente, às necessidades das pessoas e do país.

Morei na Europa entre 1968 a 1975 e tive a oportunidade, durante meu doutorado, de visitar Foulkes, em Londres, diversas vezes. Meu doutorado é sobre a obra dele. Ele me dizia: "apesar de psicanalista, eu trabalho no grupo primeiro 'o que, depois o como, depois o para que e o quando e o porquê, aqui e agora'". Esse seu jeito de trabalhar, fenomenologicamente, lhe trouxe muitos dissabores por parte de Ernest Jones e de Melanie Klein que, na época, eram grandes nomes da psicanálise e que, juntamente com ele, compunham o Instituto de Psicanálise de Londres.

Foulkes desenvolveu os conceitos de "rede de comunicação" e de "matriz" como sendo os principais conceitos instrumentais de seu trabalho. Isso significa que ele não trabalhava o conceito de resistência grupal a partir de uma visão psicanalítica, mas sim a partir do conceito de campo, pois sabia que o grupo, como um campo, formava sua própria resistência e assim devia ser analisado.

Discípulo de Foulkes, aprendi com ele a ver, no método fenomenológico, um grande instrumento de trabalho, que ele intuíra pela Teoria do Campo de Lewin e da Teoria Holística Organísmica de Goldstein.

Daí para a Gestalt Terapia foi apenas uma passagem. Devo dizer que Foulkes me levou para a Gestalt Terapia, porque esta, mais que a psicanálise, me dava respostas práticas e mais próximas de uma compreensão dinâmica e operacional do comportamento humano, que era o que Foulkes também buscava em Lewin e em Goldstein.

O artigo publicado fica como está, pois ele conserva uma impressionante atualidade, se visto a partir da perspectiva psicanalítica com que foi escrito. Eu, porém, não estou mais lá. A Teoria do Campo, a Holística e a Psicologia da Gestalt me levaram a uma compreensão diferente da resistência, que é o que passo a apresentar em seguida.

\section{A resistência numa visão fenomenológico-existencial}

Tire todas as resistências, todas as confluências e todas as outras resistências, o que restará não será definitivamente 'contato', pura e simplesmente, mas apenas uma completa fusão, talvez até um corpo morto, um caminho da decomposição,o qual estará completamente e pela primeira vez fora de contato. (Wheeler, 1991, p. 113).

A Gestalt Terapia é definida como terapia do contato e do encontro, o que significa uma postura, necessariamente, relacional. O ser humano é um ser-do-mundo e para-o-mundo e o outro integra, permanentemente, o sujeito com o qual está em contato. Estar em contato é, portanto, um processo resistencial, no sentido de que o outro sempre me faz face. Resistir é um processo existencial, natural e parte essencial do comportamento humano.

Temos uma visão próxima à da física e da elétrica que define assim a resistência:

resistência é a propriedade que tem toda substância de se opor à passagem da corrente elétrica e que é medida, em um corpo determinado, pelo quociente de tensão contínua aplicada às suas extremidades pela corrente elétrica que atravessa o corpo. (Gordon Wheeler, 1991, p. 113).

Qualquer força, portanto, que se oponha a outra chamase resistência, independentemente de qualquer finalidade secundária que o encontro dessas duas forças possam ter.

A finalidade da resistência no ser humano é idêntica: ela se opõe à força de uma energia que ameaça interromper o equilíbrio sujeito-mundo. Os corpos resistem, naturalmente e em um primeiro momento, a qualquer força que possa ameaçar seu equilíbrio interno. É o que chamamos de instinto de autopreservação. Se o organismo, na sua sabedoria instintiva, não considera uma determinada força intrusiva e destrutiva: ele aciona um segundo instinto, o de auto-atualização, que lhe permite incorporar o estímulo interveniente. O organismo sabe e reconhece, imediatamente, o que é bom para ele, o que traduzimos por: o organismo segue sempre a lei da preferência. Às vezes, a própria doença é um grito desesperado do organismo, protestando contra sua função cognitiva que insiste em impor ao corpo algo que o organismo rejeita.

$\mathrm{O}$ aspecto fenomênico, portanto, da resistência é ter a função de controlar o fluxo energético de uma força exterior que tenta se sobrepor e romper a auto-regulação organísmica. Quando falamos organismo, estamos falando da pessoa como um todo no mundo, convictos de que o dentro e o fora são apenas lados a partir dos quais olhamos a realidade. O fluxo, portanto, tem um duplo movimento, de dentro para fora e vice-versa. Chamamos esses movimentos de equilibração espontânea e equilibração natural.

Equilibração espontânea é aquela que procede de leis internas do processo da relação eu-ambiente e independe da vontade da pessoa. Com a pessoa em homeostase perfeita, a relação harmônica entre seus diversos sistemas ocorre naturalmente e o organismo está dinamicamente em repouso. Chamamos esse processo de centragem organísmica, por entendermos que existe na pessoa um centro ou uma central a partir da qual o organismo se auto-regula.

Equilibração natural é o processo que surge das exigências do organismo, sempre que um elemento estranho tenta penetrar em um de seus sistemas, produzindo um desequilíbrio. Nesse caso, a homeostase se encontra em perigo e o organismo libera, naturalmente, suas defesas à procura de um ajustamento criativo, buscando no meio ambiente aquilo de que precisa para se auto-regular. É o que chamamos de equalização.

O processo da resistência independe, portanto, da vontade da pessoa ou de provocações do terapeuta. O organismo resiste naturalmente sempre que está diante de um objeto possivelmente ameaçador.

A resistência, portanto, do ponto de vista de processo, é uma necessidade organísmica, não se podendo pensar uma terapia sem resistência, pois a matéria do processo terapêutico é basicamente constituída dos processos resistenciais, que são complexas formas de contato entre a pessoa e seu meio ambiente.

A resistência, entretanto, se torna neurótica quando o organismo dispara indiscriminadamente seus processos de defesas, provocando um bloqueio entre suas necessidades, 
apenas detectadas e a realidade circunstante, mas, se uma dada resistência é já parte integrante do funcionamento da personalidade, o ato de resistir eficazmente poderá ser considerado como uma retirada técnica, uma finalização do ciclo de experiência, que é o que chamamos de equilíbrio instável ou provisório.

Estamos saindo do conceito de resistência como algo que deve ser derrubado, destruído, para um conceito de que deve ser observado criteriosamente, estudado profundamente e até cuidado religiosamente.

\section{Buscando uma definição}

A resistência é em si um mecanismo de defesa da angústia e da ansiedade experienciadas como insuportáveis pelo indivíduo. Não é um termo unívoco, como se fosse um processo global e independente, entendido igualmente pelas pessoas. Ela tem muitos significados, enquanto considerada em si e enquanto considerada na sua relação com diferentes situações vividas pelas pessoas. Considerada tradicionalmente como um mecanismo de defesa, apresenta vários nomes ou divisões didáticas de uma única realidade e, nesse caso, é chamada projeção, introjeção, etc.

Como na física, a resistência psicológica assume um papel controlador e protetor, passando a ser um instrumento de vital importância na regulação do objeto com seu meio circundante, podendo-se dizer que a experiência da resistência ocorre no campo físico-existencial da pessoa, intensificando-se na fronteira na qual o contato entre pessoa e meio se torna mais claro e, às vezes, premente, porque aí forças opostas se debatem na tentativa de vencer uma à outra.

A resistência de alguém ou de um grupo é a expressão do sistema interno de relações que a pessoa ou o grupo estabelece com o mundo e, enquanto uma situação de compromisso, a resistência nos fornece as informações necessárias para se entender como o sujeito ou o grupo estruturam uma percepção de si e da realidade. Assim, podemos falar de uma resistência intragrupal que se expressa pela matriz grupal e que revela o caminho da constituição da própria resistência e de uma resistência interpessoal, que nasce da subjetividade de cada membro do grupo, como um processo singular e individual para se defender do outro, enquanto o outro. $\mathrm{O}$ outro, enquanto outro, é o mundo que lhe faz face e é dessa percepção que nascem todos os movimentos resistenciais.

O grupo convive, o tempo todo, com um duplo movimento, o de estar junto para a produção de uma unidade ou entidade dinâmica, ou seja, o grupo forma uma unidade de matriz e, de outro lado, os indivíduos, como o grupo, têm um instinto de completude, de formar todos criativos e o de separar-se, no sentido de que cada um, embora dentro de um processo grupal, conserve sua identidade. O grupo é, portanto, um treinamento constante de como estar junto sem que cada um perca a própria identidade e de como separar-se sem perder a coesão intragrupal. Esse duplo movimento de unir e de separar cria a impermanência e, ao mesmo tempo, a interdependência grupais, processos por meio dos quais o grupo se mantém como um campo constante de força e de energia de mudança.

\section{Natureza da resistência}

Do ponto de vista individual, o eu usa uma defesa quando um impulso está em conflito com uma proibição. A resistência, portanto, é algo que ocorre entre um impulso e uma proibição. Em toda defesa existe, pois, algo reprimido, criando um equilíbrio frágil, porque ele é uma situação de compromisso entre a consciência do desejo e sua negação. $\mathrm{O}$ material introjetado pelo sujeito e posteriormente reprimido não consegue ser projetado, permitindo que um determinado mecanismo se instale como um pseudo-elemento equilibrador e de compromisso entre sujeito e realidade.

Nesses casos, o que ocorre entre o impulso e sua proibição é que tanto o indivíduo quanto o grupo não se sentem seguros e segurança é fundamental no processo de desbloqueio da repressão. A resistência surge quando o organismo ou o grupo não tem acesso às suas verdadeiras motivações e não se sente com permissão para se expor. A resistência é um mecanismo de prevenção e o grupo, ao longo de seu processo, vai formando sua própria resistência.

Temos definido a Gestalt Terapia como um processo de contato e de encontro da pessoa com o mundo. Enquanto uma forma normal de encontro e de contato, a resistência pode ser definida como uma forma de prevenção primária na qual o desejo pode seguir o seu curso sob o olhar vigilante da resistência. Quando ela se torna neurótica, estamos falando de prevenção secundária ou terciária, quando a resistência persegue o desejo e o confronta com sua proibição. $\mathrm{O}$ ser humano resiste e, ao resistir, ele se diferencia do mundo e a resistência se transforma num mecanismo que identifica nossa identidade por meio de nossa subjetividade.

Dizemos que tudo tem dois ou mais lados, a resistência também, pois ela tem uma função externa de provocar no grupo um silencioso cuidado pela sua manutenção e uma função interna criativa de, no afã de se defender da realidade externa, fazer com que o grupo termine por criar novas habilidades que lhe permitam que novas funções e papéis se desenvolvam no seu interior.

As resistências estão diretamente ligadas a três processos de contato que mantêm o grupo dentro de um equilíbrio estável: estamos falando de mudança paradoxal, de ajustamento criativo e de auto-regulação organísmica, processos pelos quais as pessoas no grupo se transformam em pessoas do grupo, sendo que a sensação de pertencer é o elo que constitui e motiva realmente o grupo a evoluir.

Quanto mais doente um grupo, tanto mais ele terá dificuldades de mudanças. Sabemos que a dificuldade de mudar está ligada a uma série de medos, como medo da própria liberdade, medo de assumir o poder e o controle de si mesmo. Esses medos individuais são incorporados à matriz grupal que termina por provocar nas pessoas as mesmas sensações de que o risco deve ser evitado a qualquer custo.

Trabalhamos no grupo em três níveis que, por sua vez, representam três modalidades de processos transferenciais: 1) Terapia em grupo, que é quando elegemos uma pessoa e cuidamos dela no grupo, como se ela estive sozinha com o terapeuta no seu consultório. Nesse caso, o grupo não interfere e é um mero expectador. 2) Terapia de grupo, que é quando uma pessoa se torna figura para um trabalho e o 
terapeuta não só pede aos colegas de grupo que interfiram, como eles o podem fazer espontaneamente. Nesse modelo, é fundamental que o terapeuta não perca de vista que ele deve manter a pessoa o tempo todo como figura. 3) Terapia do grupo, quando o grupo se transforma no cliente e o terapeuta trabalha a produção do grupo. Esses três modelos retratam três modos de trabalhar o contato no grupo, não importa o tema em questão. Representam níveis de ação, de comprometimento e de aprofundamento. Não podemos esquecer que as resistências são sempre complexas formas de contato e de encontro com a realidade.

Mudar é provocar e tentar conviver com situações novas. Nesse processo, a ansiedade ocupa um papel fundamental e ela sinaliza o grau de repressão do desejo e a proibição interna da mudança.

Conhecer o processo interno da resistência grupal é perceber a estrutura interna em que ela se funda, é conhecer os caminhos que as motivações internas percorreram até se transformar em resistência. Não se trata, pois, de lidar com a resistência em si, mas com o processo ou elementos que ela contém. Não se trata de, simplesmente, destruí-la ou modificá-la, mas entender suas razões, pois a resistência tem uma função protetora e equilibradora.

Já falamos que resistências são complexas formas de encontrar ou de fugir da realidade em forma de contato. Um dos modelos gestálticos de estudar o contato humano é o que temos chamado de "Ciclo do Contato" (Ribeiro, 1997) que descreve nove formas que, classicamente, poderiam ser chamadas de mecanismos de defesa ou de resistência, mas que consideramos como mecanismos de auto-regulação organísmica por ver na resistência antes um processo de sabedoria do organismo, de cuidado existencial que de destruição.

O Ciclo contempla também, para cada forma de mecanismo não-saudável, uma forma saudável, que chamamos de Ciclo da Saúde. Assim, seguindo o modelo do Ciclo, se a resistência é introjetar, o caminho será o de mastigar e de se movimentar no sentido de uma adequada solução; se é projetar, o caminho é o de reter, de uma espera criativa que possa dar à pessoa verdadeiras saídas do problema; se é retrofletir, o caminho é o de trocar, de encontrar saídas para o mundo e não saídas que terminem prejudicando a própria pessoa; se é defletir, o caminho é focalizar, concentrar, procurar caminhos de criatividade.

Tanto o grupo como o indivíduo perfazem essa caminhada entre a doença e a saúde. Nesse nosso modelo, entretanto, a resistência não é vista como algo fixo, estruturado, mas sempre tendo do seu lado um pólo pelo qual a resistência deixa de ser vista como um sintoma para ser vista como um processo natural e humano, embora a ser mantida sob cuidadosa e amorosa observação.

\section{Resistência como contato}

A consciência, a priori, de que a resistência é mais uma forma de contato do que de destruição nos coloca diante dela, imediatamente, com um olhar mais de observador do que com um olhar de proteção. Resistência não é um construto entendido idealmente de forma idêntica por todas as pessoas. Ela é relacional, portanto sujeito a mudanças. No grupo, assume formas grupais ou individuais sendo sempre uma função do ambiente, ou seja, ela acontece no "entre" das fronteiras dos sujeitos, individualmente, entre si, do sujeito com o grupo, do grupo para com um de seus membros ou do grupo com ele mesmo, como um todo, e de todas essas possibilidades para com o meio ambiente. É o que chamamos de resistência, transferência ou contratransferência múltipla grupal. Não entendemos aqui resistência, transferência ou contratransferência como processos psicanalíticos provocados pela sua técnica em ação. Entendemos esses conceitos como processos naturais e humanos que podem acontecer entre dois seres em relação em qualquer circunstância e com os quais trabalhamos fenomenologicamente.

Esse movimento de resistir e acomodar-se, de ter que organizar suas próprias fronteiras e alargá-las ao mesmo tempo, é fundamental para o crescimento do grupo, pois, sem fronteiras claras, o grupo cairá num fundo caótico e, com fronteiras rígidas demais, perderá sua capacidade de mudar e ser criativo. Um nível de tensão optimal é importante para que o grupo não se acomode e possa criar seus próprios caminhos, ou seja, experiencie um ajustamento criativo, no qual sempre se perde algo, mas se encontram caminhos novos e sem os quais o grupo poderia ser destruído pela sua própria energia.

Podemos dizer que a resistência, enquanto contato, é paradoxalmente transformadora, pois o organismo não cria um sistema de autodefesa a partir do nada. A resistência é essencialmente um sistema de trocas. Surge como uma solução provisória para uma situação de cujos caminhos a mente ainda não tomou consciência. Aqui, a parte, por uma inteligência orgânica ou talvez emocional, assume uma função protetora ou de ajustamento criativo do que, aparentemente, seria uma função do todo.

Não percamos a perspectiva de que estamos falando de resistência ou resistências como formas de contato grupal. Essas formas de contato finalizam processos individuais que, psicodinamicamente inter e intraligados, formam o que chamamos de matriz grupal. A matriz pode ser definida da seguinte maneira: atmosfera de grupo, cultura grupal, talvez até de inconsciente grupal, se pensamos o inconsciente como uma relação de procura entre parte e todo, entre figura e fundo, entre organização e caos. A matriz se transforma em uma "co-terapeuta" como geradora de processos novos e facilitadores da mudança em grupo ou do grupo.

Tanto a matriz quanto os indivíduos têm ou formam processos resistenciais específicos. Quando ocorrem na matriz, elas pertencem ao grupo como um todo e, quando ocorre no indivíduo, temos de pensar que é sua e do grupo ao mesmo tempo. Na verdade, em um grupo, só didaticamente, podemos dizer que a resistência é de um ou do outro, porque, olhando holisticamente o grupo, temos de dizer que tudo é uma coisa só e o que muda é a perspectiva a partir da qual o sujeito olha o objeto sob observação. A resistência expressa o modo a partir do qual o grupo organiza seu contato em um dado campo.

Toda a realidade acontece em um dado campo e a resistência acontece em um dado campo e em dado momento. Nada acontece antes ou depois, pois o que está acontecendo é o que devia estar acontecendo, tanto que está acontecendo. 
A resistência tem que ser vista como algo que acontece em um dado campo estruturado, como um processo no campo e do campo, como modos pelos quais indivíduos e grupos organizam seu aqui e agora, na sua relação eu-mundo, a partir da significação que ele confere à realidade fora dele.

Resistência é uma palavra do terapeuta. O cliente não está resistindo, ele apenas está funcionando de um determinado modo que eu classifico como resistência para poder ter um mapa e me organizar científica e metodologicamente. O cliente não está resistindo, simplesmente constituiu um modo de funcionar que, provisoriamente, o ajuda a levar a vida sem muitas angústias e ansiedades. Temos, portanto, de passar do conceito de resistência, como resistência ao contato, para resistência à awareness, pois é a awareness que qualifica o contato, organiza o campo, sinaliza o processo, leva à intencionalidade transformadora, isso é, a um sentido seja para o indivíduo seja para o grupo que lhes permite agir em consonância com a experiência vivida.

Na realidade, quando alguém resiste, não está resistindo só ao contato, até porque não tem como resistir sem estar em contato, pois resistir é já um ato de contato. Resiste-se à consciência que o contato pode produzir na pessoa, porque, ao ser percebida como tal, poderia levar a soluções para as quais a pessoa não está preparada. De outro lado, consciência é contato. A diferença é que a awareness, enquanto contato, nos coloca em contato com as razões do contato e isso é profundamente ameaçador para quem não tem suporte interno para lidar com certos de tipos de mudança. Afinal resistência tem a ver com medo de mudança.

Atrás do triângulo contato-consciência-resistência, ocorre um duplo processo. Estamos falando de permanência e de impermanência ou, com palavras mais simples, de conservação e crescimento, dois processos internos e necessários ao desenvolvimento natural do ser humano. O grupo vive, o tempo todo, esse duplo movimento, representado por diferentes pessoas. O grupo evolui sempre e, a cada sessão, a matriz se reorganiza pela incorporação de novos processos. A matriz tem uma teleologia que lhe é própria, baseada no instinto de autopreservação e de auto-atualização, imanente em cada um de seus membros e que, energeticamente, é transferido para matriz grupal, ao longo de seu processo de formação, conservação e transformação. A questão é saber como o campo se organiza se conservando e, ao mesmo tempo, se transformando. O contato é a força permanente do crescimento e a consciência emocionada é o veio que garante e produz mudanças.

Conservação, transformação ou crescimento são funções do contato. O processo de mudança é uma linha contínua entre conservar-se e mudar-se. A resistência também se coloca entre esses dois processos. $\mathrm{O}$ grupo procura a mudança e a teme, ao mesmo tempo. Fantasia e realidade andam juntas nesse processo de busca de autoconhecer-se para se transformar. O tempo é fator importante no processo de mudança; o grupo vai abandonado seu medo de mudança, percebendo que conservar-se é pagar uma conta de uma mercadoria que nunca nos chegará às mãos e que mudar, transformar-se, é desenvolver uma crença no próprio poder de se assumir, de vez, como pessoa.

\section{Os modos da resistência}

Resistências podem ocorrer a qualquer momento no grupo e em qualquer direção, assumindo as mais variadas formas como atrasos, falhas não motivadas, resistência à entrada de novos membros, ao término do grupo, resistência a qualquer tipo de mudança, sem falar das formas clássicas de acting outs, bode expiatório, complacência com um determinado membro, silêncios, e até à própria forma de condução do grupo.

Resistir é sempre fruto de uma necessidade interna dos participantes, enquanto indivíduos e do grupo como um todo, quase sempre provocada pela dificuldade de seus membros de distinguir os verdadeiros dos falsos problemas do grupo, por uma dificuldade natural de perceber o grupo como um todo ou de assumir que tudo que acontece no grupo é uma produção do grupo.

Sabemos que a resistência pode e ajuda a manter o equilíbrio do grupo e dos indivíduos, enquanto uma tentativa de deixar tudo como está para evitar ansiedades pela escolha por coisas novas e sabemos também que, quando tratada prematuramente, pode provocar regressões em pessoas mais frágeis e provocar medo e ansiedade diante da possibilidade de ter que lidar com um instrumento cujo manuseio é ainda ignorado ou temido e cujo resultado pouco ou nada se sabe. Como uma situação de compromisso, a resistência tem que ser vista com muito cuidado e até com a proteção do terapeuta, sobretudo quando as pessoas no grupo ou o grupo se sentem ameaçadas diante de novas atitudes que demandem coragem e determinação.

A resistência é uma força, uma energia, um instrumento de controle de uma realidade difícil que nasce do fato de que não renunciamos facilmente a algo que aparentemente nos traz benefícios. É preciso ver os membros do grupo e o grupo como um processo em ação multidirecionada na qual todas as direções são possíveis, desde que promovam o bem-estar do grupo e de seus membros. A resistência não surge como algo contra o indivíduo ou grupo, mas algo do indivíduo ou do grupo ou de ambos. Como uma produção do grupo, a resistência pode, às vezes, significar uma busca desesperada do sentido do próprio caminho, um basta a qualquer intervenção, mas, nessa caminhada, o medo da dor e do sofrimento pode fazer com o grupo termine também por boicotar os movimentos de renovação confundindo o risco da mudança com a mudança do risco.

Resistir pode dar ao grupo a sensação de uma realidade pensada e sob controle. Tanto no construir a resistência quanto no desfazê-la, o grupo vai adquirindo posturas que antes não possuía. Isso não significa que vai deixando de ser ele, mas, antes, que vai se tornando ele mesmo, ao seu modo. Assim como um rio não passa duas vezes pelo mesmo lugar, nas mesmas circunstâncias, também o grupo não retorna exatamente onde já esteve alguma vez. Essa sensação de impermanência gera no grupo um desejo profundo de chegar a um lugar no qual ele possa, de fato, parar e descansar. Somos totalmente novos a cada momento que passa e é essa reestruturação consciente e permanente que nos dá o sentido da vida. Resistir é, num primeiro momento, tentar encontrar com as próprias pernas o novo caminho para casa. 


\section{O terapeuta resiste}

R. Hycner (1995) faz algumas ponderações que me parecem importantes. Diz ele que defesa atrai defesa, que resistência encontra resistência e que um dos problemas da terapia é o terapeuta ver a resistência apenas como uma coisa do cliente e que nada exacerba mais a resistência do cliente do que a resistência do terapeuta, ao mesmo tempo em que poderá criar um profundo impasse terapêutico.

De fato, a resistência do terapeuta acontece e pode assumir as mais variadas formas, como interpretações constantes e históricas que desnudam o grupo e lhe tiram o poder do próprio sentido, postura de endeusamento, não permitindo ao grupo nenhum tipo de confronto, privilegiamento de temas ou pessoas no grupo, abandono de temas ou pessoas que acirraram contradições, negação de analisar as próprias contratransferências e muitas outras.

Por outro lado, querendo ou não, o terapeuta de grupo se transforma num objeto transferencial por excelência. Ele é visto, é sentido, é amado, é desejado, é odiado independentemente de sua abordagem. Ele, por mais cristalino que seja, é sempre uma figura misteriosamente poderosa. Tal fato independe da prática terapêutica dos membros do grupo. Ele é simbolizado, fantasiado sempre, independentemente de para quais direções caminham essas fantasias e, de um modo geral, o grupo lhe acredita competência, dedicação, sensibilidade, capacidade profissional.

Estamos diante de dois movimentos: de um lado as possíveis resistências do terapeuta e do outro lado, sentimentos, emoções, atribuições que a realidade ou a generosidade dos membros do grupo creditam ao seu terapeuta.

Dependência, ataque e fuga, combinação por pares (pairing), já dizia Bion, são grandes movimentos humanos que se sucedem no processo do grupo de se tornar, de fato, um grupo. Resistência e admiração de ambos os lados são também processos humanos de constituição daquilo que somos ou queremos ser.

Resistir é apenas um processo, profundamente humano, de optarmos por nós mesmos quando dados de realidade não conseguem juntar coração, mente e pernas num só processo de decisão.

Que pena que a resistência seja, quase sempre, uma opção pelo mais difícil, mas que, naquele momento, nos parece o mais viável ou o mais fácil.

\section{Conclusão}

Ao fazer a releitura de dois de meus textos feitos em épocas diferentes e que, naturalmente, retratam dois momentos de meu pensar acadêmico, não estou comparando um texto a outro texto, estou olhando de um ângulo diferente uma única realidade que se manisfesta de modo diferente. A visão psicanalítica está voltada para a temporalidade e o tempo tem um papel importante na compreensão de como um sintoma se constitui no quotidiano das pessoas. A visão de campo, fenomenológica, está voltada para a espacialidade, ou seja, para a relação que o sujeito estabelece com seu meio ambiente, aqui-agora. A resistência para a psicanálise começa lá, para a fenomenologia começa aqui e é desse "aqui" que procede toda e qualquer explicação.
Assim:

Resistência em psicanálise é uma barreira que precisa ser vencida e removida pelo terapeuta; em Gestalt, é algo que precisa ser visto como uma forma de expressão do indivíduo, como um sintoma para o qual ele continua buscando uma equilibração, uma auto-regulação, mesmo por meio de um equilíbrio frágil e inadequado à expressão de sua totalidade.

Fenomenologicamente:

A resistência emerge de um desejo que não pode ser realizado, tendo em vista que regras e limites impostos pela realidade e que cercam o cliente impedem que esse fluxo de energia se realize como ele deseja.

Resistência é uma forma de contato que também expressa uma positiva oposição de forças que mobilizam o ser humano estabelecendo um nível mínimo e saudável de tensão, a fim de que a pessoa possa se disponibilizar para uma tomada de decisão e subseqüente ação.

Resistência é uma forma desesperada do organismo tentar recuperar sua homeostase por meio das trocas que a relação indivíduo-mundo ameaçou romper.

Toda ameaça de romper a equilibração que mantêm o organismo, mesmo inadequada ou já adoecida, gera um movimento não consciente de resistência que pode parecer tão natural que termina por escapar à observação tanto do terapeuta quanto do cliente.

A resistência se torna neurótica quando mobiliza um número enorme de defesas, impedindo que as reais necessidades do sujeito emirjam, passando ele a obedecer regras e limites sem processá-las, porque elas se colocam entre seu desejo e a proibição de realizá-las.

$\mathrm{O}$ indivíduo resiste para reduzir níveis de ansiedade e angústia que as trocas com o meio desencadearam nele, em razão da sua oposição aos seus desejos. É um meio de exercer algum tipo de controle sobre a realidade, imobilizando-se para não se permitir ser invadido.

Resistência é, portanto, uma das formas que o indivíduo encontrou para conciliar desejo, proibição e realidade e assim manter-se no controle de suas emoções, embora, por vezes, tenha que pagar um alto preço para manter a sensação de que sua relação com o mundo se encontra equilibrada.

\section{Referências}

Foulkes, S. H. (1948). Introduction to group-analytic psychotherapy. London: Ed. Heinemann.

Foulkes, S. H. \& Anthony, E. J. (1957). Group psychotherapy. The psychoanalytic approach. Harmondsworth: Penguin Books.

Hycner, R. (1995). De Pessoa a Pessoa Psicoterapia Dialógica. São Paulo: Summus.

Ribeiro, J. P. (1989). O conceito de resistência na psicoterapia grupo-analítica: repensando um caminho. Psicologia: Teoria e Pesquisa, 5(1), 123-135.

Ribeiro, J. P. (1994). Gestalt Terapia: O processo Grupal. Uma visão fenomenológica, da Teoria do Campo e Holística. São Paulo: Ed. Summus.

Ribeiro, J. P. (1997). O Ciclo do Contato. São Paulo: Ed. Summus.

Wheeler, G. (1991). Gestalt Reconsidered. A new approach to contact and resistance. Nova York: Gardner Press. 